\section{As emoções em campo jurídico: o argumento da experiência vivida}

Emotion in the legal field: the lived experience argument

Rubens DAMASCENO-MORAIS (UFG) r.damasceno.morais@uol.com.br

Recebido em: 13 de out. de 2018. Aceito em: 15 de fev. de 2019.
DAMASCENO-MORAIS, Rubens.

As emoções em campo jurídico: o

argumento da experiência vivida.

Entrepalavras, Fortaleza, v. 9, n. 1, p.

170-189, jan-abr/2019.

Resumo: Este artigo propõe uma discussão no domínio da argumentação e da retórica, a partir da análise de um julgamento em Segunda Instância de um tribunal brasileiro, acerca de um dano moral, num caso de falso-HIV. O texto se empenha em mostrar de que forma a experiência pessoal de um magistrado interfere na formação do entendimento de uma sentença, sem que isso signifique um movimento falacioso no processo jurídico. Para isso, o artigo traça um rápido percurso em diferentes formas de racionalidade (lógica formal, lógica informal, argumentação em contexto de interação), buscando situar o campo epistemológico no qual a discussão proposta se situa. Em seguida, discute-se a construção da racionalidade em território jurídico, apontando as características de um enunciado no campo das leis, além de se refletir sobre o Direito como território fértil para a construção argumentativa de sentenças. O trabalho apresenta ainda, no estudo de caso, o "argumento da experiência vivida", o qual nos leva a refletir sobre o quão próxima está a "letra" do "espírito" da lei. Com respaldo na discussão teórica suscitada, convidamos autores como Plantin (2011; 2016), Perelman (1989; 1990; 1999; 2002), Angenot (2008), Doury (2003), entre outros especificamente do território jurídico, para nos ajudar na empreitada de discutir o papel das emoções nos textos da lei.

Palavras-chave: Argumentação. Emoções. Tribunal. 
Abstract: This article proposes an argumentative and rhetorical study of a judgment in a Second Instance Court in Brazil, in a moral damage case about false-HIV. The text intends to show how the personal experience of a magistrate steps in the formation of the understanding of a sentence. For this, the article traces a research in different forms of rationality (formal logic, informal logic, argumentation in context of interaction), seeking to locate the epistemological field in which the proposed discussion is situated. We discuss yet the construction of rationality in legal territory, pointing out the characteristics of a statement in the field of laws, in addition to discussing Law as fertile territory for the argumentative construction of sentences. In the case study, the paper also presents the "lived experience argument", which leads us to reflect on how close are the "letter" and the "spirit" of the law. We invited authors like Plantin (2011; 2016), Perelman (1989; 1990; 1999; 2002), Angenot (2008), Doury (2003), among others specifically of the legal territory, to help us in the task of discussing the role of emotions in the texts of the law.

Keywords: Argumentation. Emotion. Tribunal.

\section{Introdução}

Este trabalho inicia-se com um grande "sim" à questão: "É possível que as emoções contribuam para a construção de uma sentença judicial?". Nesse sentido, propomo-nos a analisar, a partir do excerto de um julgamento em tribunal de Segunda Instância brasileiro, de que forma a experiência pessoal de um magistrado pode interferir na formação de seu entendimento acerca de um caso em julgamento, sem que isso signifique um movimento falacioso no processo jurídico. Para isso, dividimos este artigo em quatro partes. No primeiro momento, traçamos um rápido percurso sobre diferentes formas de racionalidade (lógica formal, lógica informal, argumentação em contexto de interação), buscando situar o campo epistemológico no qual a discussão se insere. No segundo momento, discutimos a construção da racionalidade em território jurídico, apontando, inclusive, as características de um enunciado no campo das leis, além de discutirmos o Direito como território fértil para a construção argumentativa de sentenças, apesar de certa crainte révérencielle, ou seja, certo receio de falarmos sobre leis sem sermos juristas. Na terceira parte, apresentamos os aspectos metodológicos que nortearam a utilização dos dados que aqui analisamos e, por fim, apresentamos um estudo de caso.

A principal contribuição deste trabalho é adentrar o universo das leis - muitas vezes bastante controverso -, sob o ângulo da análise do discurso, dos estudos interacionais, argumentativos e retóricos. Aqui oferecemos uma instigante maneira de descrevermos o mundo das cortes e tribunais, na iminência de contribuir com análises que mostrem, na prática, como funciona esse arcabouço social, sob o prisma da perspectiva argumentativa. 
V. 9 (1)

170-189

jan-abr

2019

\section{Argumentação e emoções}

Longe de constituir um tema tranquilo, os estudos no domínio da argumentação estão longe de ser unanimidade, e a efervescência teórica desde a segunda metade do século XX já deixa isso claro: Perelman, Toulmin, van Eemeren, Ducrot, Walton e outros. Aliás, há algumas décadas, temos assistido a uma explosão de pesquisas que têm na investigação no campo da argumentação seu ponto de partida. Pesquisas recentes têm envolvido a Linguística (Linguística da língua, da enunciação, das interações), assim como os estudos ligados aos campos já tradicionais em estudos da argumentação (Lógica, Retórica, Dialética) e ainda a Filosofia da linguagem, o Direito etc. Nesse sentido, não basta apenas autoproclamar-se estudioso de argumentação, tantas e tão vastas as possibilidades de estudos nessa área. Segundo Breton e Gautier (2000, p. 68), os estudos em argumentação "formam uma nebulosa extremamente disforme em que se atomizam diferentes linhas teóricas com práticas ligadas a áreas disciplinares diversas", irrigando, assim, diversos campos do saber como a Linguística, as Ciências da linguagem, entre as tantas análises de discurso. É interessante destacar que as diferentes famílias teóricas nas quais a argumentação encontra abrigo trazem diferentes abordagens de racionalidade. Desse modo, contentamo-nos em, neste breve espaço, olhar um pouco mais de perto não apenas o território puro da argumentação, mas o entrecruzamento da argumentação com o teor emocional presente nos discursos jurídicos, o que, em termos práticos, significa uma odisseia, pois, se o simples fato de empreendermos apenas uma análise argumentativa já é tarefa árdua, mais árduo ainda (a fortiori) será falar de argumentação em domínio jurídico.

Sabemos que a perspectiva clássica nos estudos de argumentação sustenta-se em um tripé epistemológico: a lógica de um lado, de outro a dialética e, finalmente, a retórica. Não obstante, aqui prestigiaremos o enfoque dialógico e dialogal, porque os dados com que trabalhamos e analisamos recebem um tratamento diferente do que seria dado numa análise argumentativa com o cabedal da lógica. No entanto, não ignoramos que a lógica formal tem papel extremamente relevante na análise argumentativa. Tal perspectiva não será abordada aqui por simples questão de posicionamento teórico e metodológico. E a escolha pela vertente não-lógica justifica-se pela "alexitimia" da argumentação demonstrativa, uma vez que ali se banem o ethos e o pathos de seus teoremas. De acordo com Plantin (2016, p. 442, tradução e grifos nossos): 
O termo alexitimia (a-lexis-thymo: falta de palavras para a emoção) designa uma linguagem da qual toda e qualquer expressão de sentimentos de emoção é banida [...]. "Alexitimia: termo proposto por Sifneos para designar os pacientes com disfunções psicossomáticas caracterizadas por: 1) incapacidade de exprimir verbalmente seus afetos; 2) limitação para uso da imaginação; 3) privilégio da ação, em detrimento da contemplação; 4) apego ao aspecto material e objetivo das coisas, situações, relações".

No campo da lógica formal, as verdades são impessoais, e o fato de as reconhecermos (ou não) não muda em nada seu status de verdade. Por outro lado, no domínio do raciocínio dialético, ao contrário, falamos sobretudo de emoções, o que traz em seu bojo a ideia de "adesão", tão cara a Perelman e Olbrechts-Tyteca. No breve excerto do corpus que apresentaremos, os magistrados, no momento de pronunciarem seus votos, deixam transparecer um lado humano e sensível, bem distante da imagem fria e imparcial da justiça. Na interação argumentativa que selecionamos, mostraremos como um interagente contesta a tese de outro colega e, sobretudo, como eles, magistrados, em plena sessão de deliberação, gerem a aparição de pontos de vista discordantes, com base em um relato pessoal, sem que isso macule a sentença pronunciada. Desse modo, observaremos como um debatedor posiciona-se diante da linha argumentativa de outro, de modo, muitas vezes, aguerrido, apaixonado. Nesse aspecto, sentimo-nos à vontade para discutir o peso de um argumento; a força de uma estratégia argumentativa, em situação desnudada de alexitimia.

Nesse sentido, Angenot (2008, p. 75) afirma que:

[...] um argumento não é jamais demonstrativo; ele até pode, se for 'bom', se tiver 'peso', discutir a probabilidade de uma tese, tentar defendê-la ou reforçá-la; mas nada impede que outro argumento faça papel muito melhor em um debate.

Ali vemos a distância que existe entre o lado objetivo, exato e indiscutível na argumentação lógica, demonstrativa e efetiva, e a argumentação (dia)lógica, afetiva, suscetível de angariar a adesão de um auditório, a partir da qual "um orador escolhe e articula argumentos em função de uma estratégia" (ROBRIEUX, 2010, p. 44). É nesse segundo campo que situamos este artigo, pois optamos por uma perspectiva ligada à argumentação dialógica, dialogal e interacional, em contraposição à perspectiva logicista. 
V. 9 (1) 170-189 jan-abr 2019

A abordagem aqui será essencialmente argumentativa e retórica, uma vez que nos parece impraticável nos dispormos a analisar deliberações sem levarmos em consideração teorias do campo da retórica e da argumentação, desenvolvidas no seio da pragmática das interações verbais. É justamente por isso que decidimos examinar, entre outros contextos, como se faz a gestão do desacordo entre juízes em momentos de conflito de opinião, sem nos preocuparmos com esquemas lógicos. Nesse sentido, tentaremos mostrar as conexões na relação entre argumentação e emoções, o que pressupõe certo distanciamento da abordagem lógica, que, como temos insistido, é necessária para os estudos da argumentação, mas não suficiente para dar conta da descrição e análise das reentrâncias e reverberações envolvidas na troca dialogal entre interagentes.

De acordo com Plantin (2011, p. 190), podemos "argumentar as emoções [...] ou seja, fundamentar senão em razão, pelo menos por meio de bons argumentos, o 'sentir na pele' de uma situação". E, não por acaso, o excerto de que nos ocupamos aqui naturalmente nos levou a examinar de muito perto o desenvolvimento das emoções nas situações analisadas, entre juristas. Desse modo, vamos transitar por entre marcas textuais que apontam para o lado "emocionado" dos envolvidos em sessão de deliberação em Segunda Instância. Aliás, a pesquisa maior da qual este artigo é apenas uma amostra nos permitiu perceber, a contrario do que se afirma no senso comum, que o discurso jurídico também é marcado pelo lado emotivo. Desse modo, tratamos aqui de argumentação e emoções, de ethos e de pathos, o que, de forma clara, obriga-nos a buscar algo além da abordagem lógica. O objetivo aqui é ir além da busca cartesiana da evidência, sob o risco de não percebermos a "presença de toda uma herança, de toda uma cultura, e de toda uma orientação espiritual" na elaboração de sentenças jurídicas (VANNIER, 2001, p. 182, grifo nosso).

Para concluirmos esta primeira parte, retomamos a resposta à questão apresentada na Introdução: sim, as emoções contribuem para a construção ou para o desmantelamento de uma sentença (WOHLRAPP, 2007, p. 1510), pois, contrariamente ao que defendem os adeptos da corrente positivista em território jurídico, as emoções podem interferir, por exemplo, nos momentos em que os magistrados devem se posicionar acerca da qualificação de um dano moral, sobretudo em julgamentos polêmicos. Os dados de que dispomos confirmam que os juízes estão longe de serem máquinas de calcular e que, ainda assim, recorrem a aritméticas complexas que, ironicamente, escapam do território da matemática (DAMASCENO-MORAIS, 2013), como veremos a seguir. 


\section{A racionalidade jurídica}

Uma das contribuições do filósofo da Universidade Livre de Bruxelas foi insistir no fato de que há outras formas de racionalidade além da estritamente lógica. Para Perelman, a retórica se confunde com a argumentação, donde a necessidade de compreender o conceito de racionalidade de forma alternativa, de forma menos radical e mais adequada ao contexto jurídico. Dentre outras questões, o filósofo se perguntava até que ponto uma sentença teria a mesma exatidão de uma fórmula matemática ou de um teorema. De acordo com Vannier (2001, p. 188), "para Perelman, a liberdade é uma questão de retórica, na medida em que ali a racionalidade é abordada numa perspectiva argumentativa". Nesse sentido:

[...] a nova retórica ou a arte da argumentação examina os raciocínios extralógicos ou metalógicos; é precisamente tal característica que permite à subjetividade e às emoções surgirem no discurso. Em sua retórica, Perelman sugere que praticar a ciência jurídica supõe uma forma de exercício da razão prática, a phronesis. (STAMAKIS, 1995, p. 67)

Esse exercício da razão prática se manifesta nos momentos em que os indivíduos tentam encontrar soluções racionais, como o fazem os magistrados em suas sentenças, durante deliberações jurídicas, quando a busca de um consenso é um exercício fundamental de prática da racionalidade. Como se sabe, o espaço que Perelman qualifica de "razoável" é anticartesiano. E essa forma de compreender a racionalidade entreabre uma porta para a dimensão emocional, que, desse modo, encontra uma passagem para o mundo jurídico. De que outra forma poderíamos então compreender a dissociação que Perelman faz da noção de "racionalidade" se não for deste modo? O filósofo deixa claro que as questões jurídicas ficam do lado do raisonnable, e não do puramente racional. Koren (2002, p. 12) entende que:

[...] o que a Nova Retórica propõe, entre outras coisas, é precisamente a descrição e a legitimação da atitude de todo enunciador diante da argumentação; sua capacidade de tomar posições, de defender uma ideia, praticando uma forma de "racionalidade axiológica".

Em resumo, Perelman, como filósofo do Direito, aposta num "meio termo", isto é, no conceito de raisonnable; aposta num paradigma de racionalidade que deve substituir o paradigma da lógica pura. É por isso que Perelman não vislumbra uma argumentação sem retórica. 
V. 9 (1) 170-189 jan-abr 2019

As tentativas recentes de esboçar uma teoria da argumentação jurídica deixam patente o caráter dialógico, deliberativo e, obviamente, argumentativo dos debates jurídicos, os quais aspiram a uma justificação racional das soluções encontradas nas causas pleiteadas pelas partes nos processos. Desse modo, a gestão do desacordo tem papel fundamental ali, sobretudo porque o mundo jurídico só existe porque existe o desacordo que precisa ser racionalmente resolvido, caso contrário voltaríamos à Idade Média e resolveríamos tudo via Lei do Talião, isto é, no dente-por-dente. De fato, as tentativas de se compreender a argumentação em domínio jurídico foram além da forma positivista de interpretar e mesmo de compreender o mundo. Em contextos institucionais como os tribunais, sabe-se, "o discurso jurídico [nada mais é do que] a implementação da linguagem, no discurso, por meio das leis" (CORNU, 2005, p. 207).

Desse modo, e nesse contexto, será considerado "jurídico" todo enunciado que tenha por meta o estabelecimento ou a aplicação de normas jurídicas. Isso porque "a atividade jurídica é, antes de mais nada, linguageira (langagière)" (DUPRET, 2006, p. 229), sendo, portanto, lógico e pertinente lançarmos um olhar de linguistas, de analistas dos discursos - em detrimento de um olhar meramente jurídico - para os dados que exploraremos. Bertea (2003, p. 105, grifo nosso) resume bem a aproximação do jurídico com o linguageiro, quando enuncia, acerca da atividade dos magistrados:

\begin{abstract}
Os magistrados interpretam as normas gerais e a jurisprudência, qualificam os casos reais e motivam suas conclusões. Eles julgam ainda os processos, o que exige a justificação (ou a reconstrução) e uma lei que fundamente sua decisão. Precisam, desse modo, interpretar as normas e aplicá-las a situações concretas; avaliar princípios; resolver conflitos entre normas jurídicas; observar a jurisprudência; verificar e qualificar fatos e, por fim, determinar a solução mais racional para decidir um caso. Também não podem se esquecer de motivarem suas decisões. E tudo isso que o magistrado tem de fazer, na verdade, são operações cognitivas que lidam com a argumentação.
\end{abstract}

Nesse sentido, Canale-Giovanni (2009, p. 21) nos lembra que a lei é um "artefato" humano, uma criação do homem, um dispositivo social, um "artefato" intelectual e social cujas características essenciais dependem do contexto, de comportamentos humanos e de atitudes proposicionais. Em reforço a isso, e observando toda essa engrenagem do ponto de vista da linguagem, do linguageiro, das emoções, temos que "a língua das decisões e das sentenças jurídicas é uma língua natural 
e, por isso mesmo, imperfeita; sujeita a ambiguidades" (MARTINEAU, 2010, p. 403); e justamente devido a essa característica, a interpretação que um magistrado faz de um caso concreto fica muitas vezes à mercê de novas discussões (muitas vezes polêmicas), sobretudo em território acerca do dano moral, em que a própria definição de "dano" e de "moral" está longe de fazer a unanimidade entre juristas (REIS, 2010).

De fato, "é uma utopia acreditar que a lei não tem lacunas ou que ela é perfeita. E, mais, não se pode lidar com esse tipo de problema simplesmente tentando aplicar a lei de forma automática ou literal" (ALVA et al., 2007, p. 566), sobretudo porque, como já ressaltado, há um vínculo indissociável entre as leis e a linguagem; esta última, como sabemos, sujeita a múltiplas leituras. Para Perelman (1989, p. 91), uma vez mais, "a questão das interpretações, no direito, é atualmente estudada em conexão direta com estudos de problemas da linguagem". De nossa parte, nessa incursão em território jurídico, pudemos constatar que, de fato, na maior parte dos casos por nós perscrutados na pesquisa empreendida, os magistrados precisam argumentar para justificar seus votos, o que corrobora o fato de que "o direito é indubitavelmente 'argumentativo e argumentado'" (MEYER, 1999, p. 296).

Para abreviarmos a discussão, basta constatarmos que a simples existência de segundas instâncias, isto é, de cortes de revisão de sentenças proferidas por magistrados de primeiras instâncias, sugere que o raciocínio jurídico é revisável. Qualquer jurista sabe que "é possível que diante de situação análoga, e utilizando os mesmos códigos, duas cortes de segunda instância cheguem a conclusões diferentes" (PERELMAN, 1990, p. 576). Desse modo, daqui para frente procuraremos vencer a crainte révérencielle (GARAPON et al., 2008, p. 1), isto é, o "medo de tocar os deuses" (tradução nossa), tentando mostrar a pertinência e a articulação dos estudos da argumentação em contexto institucional jurídico, lançando um olhar para a língua-em-interação, no que concerne à admissão do teor emocional na costura de uma sentença, sem que isso signifique uma argumentação falaciosa ou inválida.

\section{Sobre o corpus TRIBUNAL ${ }^{1}$}

As pesquisas acerca do contexto jurídico e interações verbais vêm acontecendo desde os anos oitenta. No início, o foco era mais a tentativa de perscrutar a forma como o trabalho era realizado pelos

${ }^{1}$ TRIBUNAL é o nome do corpus que possibilitou a realização da pesquisa aqui descrita. 
V. 9 (1) 170-189 jan-abr 2019

operadores da lei (TRAVERS, 2001, p. 355). O primeiro estudo de peso acerca do Direito em contexto judiciário, no domínio da Análise da Conversação, chama-se Order in Court: The Organisation of Verbal Interaction in Courtroom Settings e foi realizado por Maxwell Atkinson e Paul Drew (1979). Sua pesquisa descreveu audiências realizadas em um tribunal irlandês, no final dos anos sessenta. Para Travers, os estudos de inspiração etnometodológica em contexto judiciário fundavam-se na análise minuciosa de gravações, feitas no intuito de se explicar/ compreender de que modo as pessoas empregavam recursos culturais e comunicacionais em audiências judiciárias. Esse tipo de pesquisa em território etnometodológico é interessante para quem se interessa pela discrepância entre as leis formais (a letra de lei) e as maneiras pelas quais as decisões judiciárias são tomadas, ao vivo e em cores, isto é, na prática. Desse modo, flagrar o momento em que uma decisão é tomada, no calor de um debate, de uma interação argumentativa, é uma forma bastante instigante de compreender um contexto, seja ele qual for (jurídico, médico, educacional etc.). De fato, sabe-se que os tribunais são "o lugar privilegiado para se observar o direito em ação, por meio dos diversos eventos que acontecem ao mesmo tempo, tais como processos civis e penais, interrogatórios, escuta de testemunhas etc." (DUPRET, 2006, p. 424). Trata-se, enfim, de "um microuniverso em que os atores sociais estão engajados em um processo de comunicação linguística, caracterizado em sua maioria pelo falar em interação" 2 .

É importante destacar que na escolha dos dados, oriundos do corpus que nomeamos "TRIBUNAL", o nosso objetivo nunca foi apresentar juízos de valor acerca do modo como os magistrados deliberam. E a renúncia a todo apelo crítico nesse sentido nos deixa mais à vontade para nos lançarmos nesse mundo "misterioso" (POSNER, 2008, p. 3) do qual apenas nos interessam questões ligadas à maneira como, em deliberações muitas vezes polêmicas, os magistrados fazem a gestão do desacordo. Apesar de termos consciência de, neste momento de descrição analítica, rompermos a barreira "mundo leigo $\rightarrow$ mundo jurídico", correndo o risco de colocar a mão em um vespeiro, uma vez que, para os juristas de formação e guardiões desse território, um não-jurista será sempre um outsider (VIGNAUX, 1979, p. 67), ainda assim acreditamos que vale o risco embrenharmo-nos em tal território, sobretudo porque nosso objetivo é meramente o de compreendermos a aplicação de algumas estratégias e conceitos do campo da argumentação, e também da retórica, num exercício de descrição analítica.

${ }^{2}$ Id., Ibid. 
Desse modo, importante esclarecer que os dados foram coletados em um tribunal brasileiro, em julgamentos de Segunda Instância, entre desembargadores em deliberação acerca decasos de danomoral. Acreditamos que se trata de uma oportunidade privilegiada de focalizarmos um pouco da dinâmica jurídica que acontece em tal contexto. Ali as questões relativas ao dano moral, mais especificamente no campo do direito privado, isto é, o Direito Civil, suscitam certa "inquietação doutrinária" (COELHO, 2009, p. 3). Isso porque tal tema ainda propicia calorosos debates no mundo jurídico e também no acadêmico. A responsabilidade civil tornou-se, sobretudo após a Constituição de 1998, um tema avesso a unanimidades em direito contemporâneo, talvez porque tal domínio exija, para além das análises e reflexões baseadas nos artigos da lei, uma reflexão filosófica e ética, como acredita Moraes (2003, p. 322).

Além da restrição procedimental, os participantes de uma deliberação jurídica em Segunda Instância se orientam pela ideia de pertinência, que, segundo Dupret (2006, p. 20 e p. 274), "remete à operação de qualificação e que consiste em achar a correspondência de um fato com uma definição jurídica formal" porque "no direito, responsabilidade, sanção e obrigação de compensação são frequentemente associadas à questão de saber se uma ação causou um dano a outrem". Vê-se assim que a missão do magistrado segue a dupla exigência descrita por Perelman (1990, p. 414), segundo a qual o juiz deve motivar seu julgamento sempre tentando responder se a lei se aplica ou não à demanda em julgamento.

Por fim, acerca do procedimento em Segunda Instância, precisamos ainda esclarecer que uma sessão de deliberação reúne três ou mais magistrados, de acordo com a natureza do caso em julgamento. Desse modo, no início de cada julgamento, o magistrado Relator (REL) expõe seu voto, já redigido antes da deliberação. Em seguida, é a vez do Primeiro Vogal (1V) pronunciar seu voto; por fim, o Segundo Vogal (2V), e que não conhece o caso tão a fundo como o relator, pronunciar-se-á para que a votação chegue ao final, isto é, para que haja um veredito (por unanimidade ou por maioria). Após a fala de $2 \mathrm{~V}$, o presidente da sessão oficializará o resultado, proclamando-o, no melhor estilo austiniano e seus atos de fala.

No caso que apresentamos a seguir, a identificação dos locutores será feita em função de seus papéis ao longo das deliberações: REL (= RELator), $1 \mathrm{~V}$ (= $\left.1^{\mathrm{O}} \mathrm{Vogal}\right), 2 \mathrm{~V}\left(2^{\mathrm{O}} \mathrm{Vogal}\right)$, tudo isso apresentado aqui de forma impessoal e anônima. Os dados advêm de julgamentos que ocorreram entre os anos 2000 a 2010. A partir desse quadro, mostraremos de que forma argumentação e emoção coadunam-se com o universo jurídico, "por trás de cada sentença proferida", como adverte Livet (2000, p. 214). 
V. 9 (1) 170-189 jan-abr 2019

\section{0 argumento da experiência vivida}

O julgamento seguinte apresenta algumas pistas de como se imiscuem razão e emoção na gestão do desacordo, em deliberação entre magistrados, em território de Segunda Instância. Devido à longa extensão do julgamento (38'30'), selecionaremos uma só sequência que corresponde ao momento em que o turno de fala é dado ao magistrado Segundo Vogal (2V) para que ele pronuncie seu voto. O caso diz respeito a uma situação de falso-positivo para um exame de HIV. Acerca desse tipo de diagnóstico (o HIV positivo), sabemos que, apesar de hoje em dia o olhar da sociedade ser mais complacente, um falso resultado para esse exame pode causar sérios transtornos (e danos morais) a uma pessoa. $\mathrm{O}$ olhar social inquisidor e inquiridor ainda subsiste, por tratar-se de doença ainda incurável e, pior, ainda associada, errônea e preconceituosamente, a comportamentos sociais considerados promíscuos. Como o corpus é de alguns anos atrás, no período do julgamento deste caso o preconceito era ainda maior, devido à desinformação acerca da doença, que "mata e desmoraliza" (l.188 da transcrição a seguir).

Nesse julgamento, o relator/REL, assim como o primeiro vogal/1V, votaram a favor da sentença outrora proferida em Primeira Instância. Eles concordam acerca da qualificação dos fatos como suscetíveis de causarem dano moral (isto é, o erro no diagnóstico). Não obstante, o Segundo Vogal/2V polemiza com seus pares, por sustentar outro entendimento. Veremos, assim, que, mesmo sendo tecnicamente "voto vencido" (a votação já estava com dois votos iguais), 2Vargumentou e defendeu seu entendimento, apoiado em sua experiência de vida, pessoal, subjetiva. Tal aspecto fica patente na sequência seguinte, que reproduz a fala de $2 \mathrm{~V}$, quando o conflito de opiniões se intensificará: 
CORPUS TRIBUNAL: Caso do falso diagnóstico para HIV

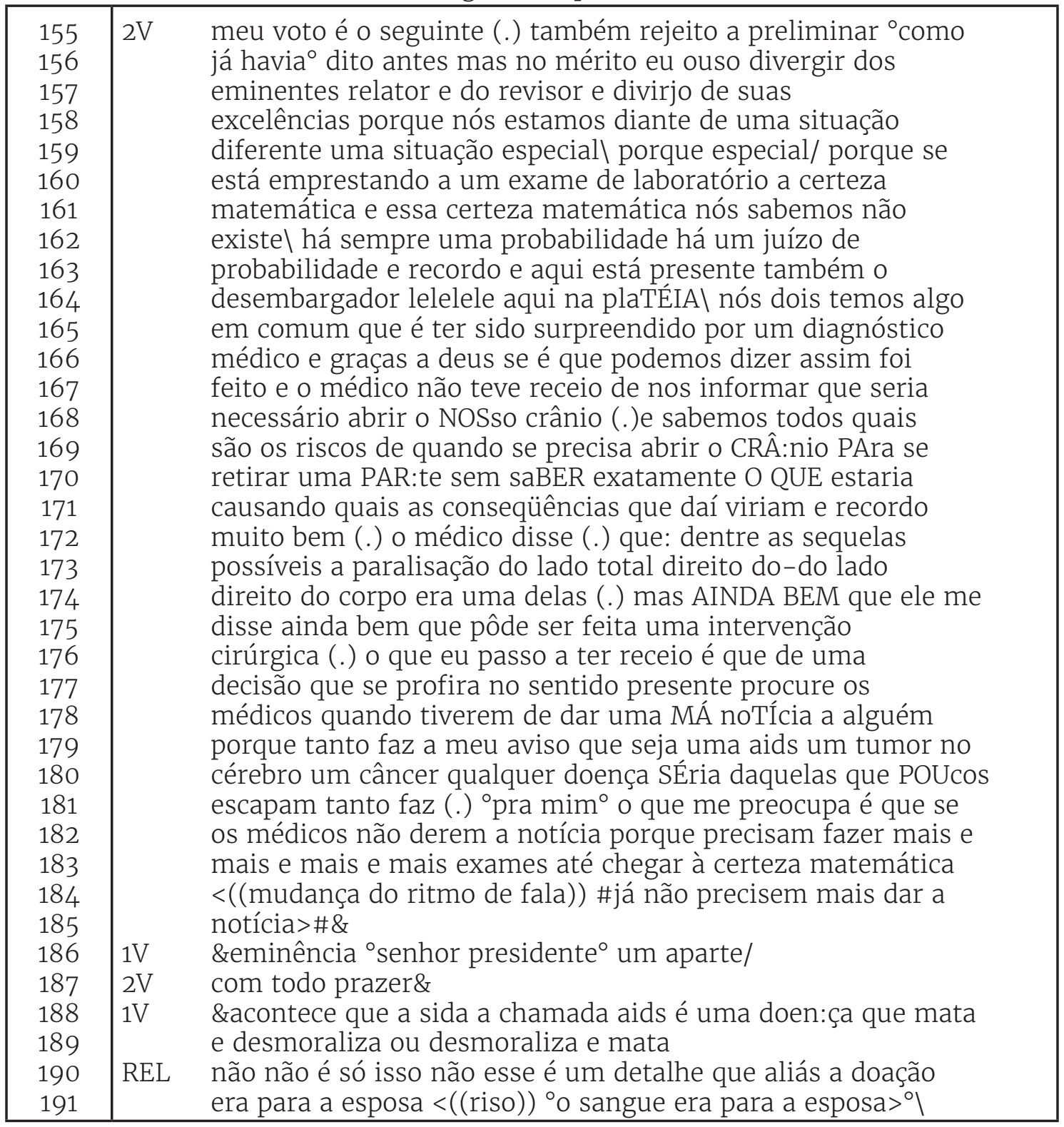

Após a adesão do Primeiro Vogal/1V ao voto do Relator/REL, vemos no excerto acima que o Segundo Vogal/2V apresenta outra interpretação para os fatos. Ali, identificamos, primeiramente, um procedimento de gestão do desacordo tão eficaz quanto recorrente nos dados de que dispomos. Trata-se da estratégia que consiste em justificar um desacordo recusando-se a aplicar o princípio da inércia, ou seja, reagir da mesma forma diante de casos similares (PERELMAN, 2002, p. 93). Em outras palavras, o magistrado alega o caráter original do caso em análise, em busca de argumento que o ajude a fundamentar a sua opinião contrária. Desse modo, após o magistrado ter ressaltado as idiossincrasias do caso ("nós estamos diante de uma situação diferente uma situação especial $\backslash$ porque especial”/ 1. 158-9), ele imediatamente relata 
V. 9 (1) 170-189 jan-abr 2019

uma experiência pessoal e que terá um papel argumentativo importante em seu voto de oposição. Martineau (2010, p. 44) provavelmente entenderia essa narrativa de cunho pessoal de $2 \mathrm{~V}$ como um "argumento de emoção", se considerarmos que, para esse autor, "um argumento pode tirar sua matéria de considerações de estado afetivo complexo que caracterizam as relações humanas". Ainda segundo esse autor, um argumento de emoção seria o oposto de um argumento jurídico e que trataria de "uma norma jurídica ou algum de seus elementos constitutivos"3.

Como se pode constatar, $2 \mathrm{~V}$ conta uma estória pessoal para reforçar a sua visada argumentativa (1.164-185). Ao buscar o assentimento de outro magistrado que fazia parte da sessão de deliberação, 2V faz uso inclusive de um outro testemunho para ratificar e dar mais autoridade a sua narrativa pessoal e dramática ${ }^{4}$. O magistrado interpelado também havia vivenciado experiência parecida com a de $2 \mathrm{~V}$, o que fica patente na fala: "nós dois temos algo em comum que é ter sido surpreendido por um diagnóstico médico" (1.164-66/2V). Desse modo, ao contar a estória da cirurgia do crânio (assim como a estória do magistrado-testemunha), 2V tenta justificar seu voto favorável pronunciado em favor do laboratório que prognosticou o falso-positivo. $2 \mathrm{~V}$ alega, na defesa de sua linha de raciocínio, que, para ele (2V), "a certeza matemática" (1.161-162/183184) é impossível nesse tipo de exame; e que se os laboratórios tivessem de esperar para ter uma certeza absoluta antes de divulgar o resultado de um exame ao paciente, poderiam comprometer um tratamento, que poderia chegar "tarde demais" (1. 184).

É dessa forma que $2 \mathrm{~V}$ justifica seu desacordo, isto é, integrando à sua narrativa um tipo de argumento a pari, em que sua experiência pessoal soaria como um tipo de "jurisprudência", além de ser uma manifestação da regra de justiça. Desse modo, $2 \mathrm{~V}$ aponta o caráter excepcional deste caso em julgamento para, de forma um tanto quanto paradoxal, encontrar um precedente (sua estória pessoal narrada) e, desse modo, privilegiar sua visada argumentativa, isto é, o entendimento de que o laboratório não teve culpa na divulgação do resultado do exame.

Ali temos o que podemos chamar de "argumento da experiência vivida" e que tem papel importante na construção do raciocínio de $2 \mathrm{~V}$.

3 Id., Ibid.

${ }^{4}$ Da sessão geralmente participam vários magistrados, mas somente três fazem parte de cada deliberação. Nesse caso, 2V, durante o seu voto, dirige a palavra a um quarto magistrado, colega seu, que apenas assistia à deliberação. 
Como acabamos de mostrar, no momento em que $2 \mathrm{~V}$ narra a estória da cirurgia que sofreu, ele leva da mesa de cirurgia para a mesa de deliberação uma justificativa para a ação do laboratório que diagnosticou o falso-negativo e, a partir daí, rejeitar a qualificação do caso como "dano moral", tentando convencer seus pares de que se trata, na verdade, de "mero aborrecimento", a contrario do que defendem seus colegas de mesa, os quais argumentam no sentido de apontar a comunicação do falso-positivo como ato ilícito, suscetível de indenização, sobretudo devido ao preconceito que pairava na época contra pessoas portadoras do vírus HIV. Desse modo, a narrativa de 2V, e que traz no seu bojo uma experiência pessoal, emotiva, funciona como argumento/justificativa para um voto contrário ao de seus pares (REL e 1V).

Por outro lado, simultaneamente, o Relator/REL e o Primeiro Vogal/1V contra-argumentam, tentando apontar um amálgama (DOURY, 2003) nos argumentos apresentados por $2 \mathrm{~V}$, o qual, segundo REL e $1 \mathrm{~V}$, faz uma aproximação errônea entre as consequências de um falso-positivo em caso de HIV e de um falso-positivo para casos de câncer. Segundo REL e $1 \mathrm{~V}$, o primeiro caso traz consequências morais ("\&acontece que a sida a chamada aids é uma doen:ça que mata e desmoraliza ou desmoraliza e mata"/l. 188-189; "não não é só isso não esse é um detalhe"/l. 190-191), enquanto no caso exames de câncer tal não aconteceria, muito pelo contrário. Um diagnóstico de câncer, sabemos, suscita pena; um caso de AIDS, preconceito.

Em suma, para REL e 1V, a experiência pessoal de $2 \mathrm{~V}$ (exame de câncer + cirurgia do crânio) não seria bom argumento em defesa de sua tese defendida (de $2 \mathrm{~V}$ ), devido ao seu exemplo (diagnóstico de câncer) ser de natureza diferente de um falso-positivo para HIV. Perelman e Olbrechts-Tyteca (2008, p. 109) falam em "hierarquia de valores" e constatam que existe um discurso do real e um discurso dos valores. Para os filósofos, "o que se opõe a um valor não deixa de ser um outro valor [...] e nada garante que na hierarquia de valores um valor não seja reconhecido pelo outro". Em verdade, a maneira pela qual os magistrados qualificam este caso tem a ver com a forma como cada um deles lida com suas próprias experiências de vida, com subjetividade e emoções, na qualificação de um mesmo fato. Aos olhos de REL e de $1 \mathrm{~V}, 2 \mathrm{~V}$, certamente devido à experiência pessoal que teve com diagnósticos de exames, está mais suscetível a fazer uma leitura diferente dos fatos apresentados. E o faz, efetivamente, como pudemos constatar, o que gerou uma estase. Toda essa hierarquização de valores 
V. 9 (1) 170-189 jan-abr 2019

e experiências culmina no emprego do "argumento da experiência vivida", o qual funciona como o gatilho responsável por justificar a atitude do laboratório (se lícita ou ilícita) aos olhos de 2V (mas não de REL e de $1 V$ ). De certa forma, ao contar a sua estória de vida, $2 \mathrm{~V}$ não deixa de demonstrar um lado emocionado e que não deixa de ter uma visada argumentativa, pois ajudará a constituir um argumento contrário à tese defendida tanto por REL quanto por $1 \mathrm{~V}$.

Nesse sentido, a partir do momento em que os magistrados deixam transparecer uma emoção (o sentimento de medo, pena, dor), podemos, acerca do que nos diz Plantin (2011), reconstruir um enunciado de emoção en amont, o que nos é possível justamente por causa da natureza dos dados, isto é, um corpus que nos possibilita transcrever as reações espontâneas dos magistrados ao longo das deliberações. Nesse sentido, para o autor, uma emoção é reconstruída en amont quando nos permite inferir o tipo de sensação/sentimento/emoção que o outro terá sentido em determinada situação ("se fulano está na situação X, então ele sentiu Y"). Govier (2010, p. 170) esclarece ainda que "muitas vezes a piedade e sentimentos afins são emoções desejáveis. Isso nos faz ficarmos atentos ao sofrimento alheio, exercitando a nossa sensibilidade e o olhar para os mais vulneráveis" o que nos parece adequar-se aos comentários feitos ao longo dessa sessão, como tentamos apontar.

Os pontos de vista desfavoráveis pronunciados pelos desembargadores ao longo de uma deliberação polêmica, assim como as reviravoltas em decisões, devem-se justamente à fluidez do conceito de 'dano moral', uma palavra-curinga. E neste momento não se pode ignorar que, para Perelman e Olbrechts-Tyteca (2008, p. 103), a justiça é considerada como um valor "abstrato". Em realidade, a tecnicidade da linguagem em campo jurídico é o fruto de uma "operação delicada" (CORNU, 2005, p. 19, tradução nossa), e que certamente está na origem do conflito de opiniões (estases) ao longo das deliberações em Segunda Instância.

Não obstante, é importante notar, a emoção externada por $2 \mathrm{~V}$ (as justificativas arroladas, entremeadas de um sentimento de pena modulado pelo seu tom de voz e também pela seleção lexical empregada durante a apresentação do seu voto) não parece ser fruto de um argumento do tipo ad misericordiam, na medida em que o magistrado não parece ter a intenção de comover um auditório simplesmente para tirar algum tipo de vantagem disso. Ali se percebe meramente um operador da lei suscetível emocionalmente pelo tipo de situação que está analisando 
(casos de doenças). Como se sabe, o argumento ad misericordiam constitui uma falácia quando tem o objetivo de camuflar um argumento fraco por meio de apelos emocionais pouco sinceros (WALTON, 1992, p. 2). A esse respeito, as reflexões de Walton nos parecem pertinentes, pois, para ele o apelo às emoções tem lugar legítimo como argumento.

Antes de concluirmos essa rápida incursão em tantas mesas (a mesa do hospital e a mesa de julgamento), entendemos que é a partir de fatos e de certos valores, e não somente a partir dos códigos e das leis, que o raciocínio jurídico se organiza. Seria um erro acreditarmos que a prática real de um sistema jurídico não está jamais isenta da dimensão axiológica. E aqui nos perguntamos, talvez retoricamente: "Deve-se interpretar a lei de acordo com a letra ou com o espírito?" (RICOEUR, 2007, p. 266). De fato, responder a tal questão é difícil, considerandose que:

[...] o texto da lei, o dispositivo de um julgamento, nada são além de reflexões acerca de situações bem reais feitas por um ser [o magistrado] que come, bebe, dorme, escreve e vive no nosso meio; raramente o mais pobre dos pobres, mas mais intelectual que a média. (ARNAUD, 1979, p. 118).

Como tentamos mostrar brevemente aqui, "emoção, personalidade, intuições políticas, ideologia, savoir-faire e experiência [podem] determinar os rumos de uma sentença" (POSNER, 2008, p. 269). Nesse campo da lógica informal, sabe-se que "mesmo quando tudo vai bem e os processos seguem seu fluxo correto de procedimentos, haverá sempre uma dúvida cruel acerca da eficácia do julgamento" (LATOUR, 2004, p. 269). Assim, percebe-se que, neste domínio, argumentar requer mais do que meros conhecimentos jurídicos: no domínio do espírito da lei, o hermeneuta não tem escolha, sendo obrigado a se posicionar acerca de questões que a Senhora com os olhos vendados e segurando uma balança na mão esquerda e uma espada na mão direita ficaria surpresa de examinar.

\section{Considerações finais}

A partir de um breve estudo de caso, este artigo tentou mostrar que, no universo jurídico, a sensibilidade de quem julga não pode ser completamente dissociada do lado estritamente racional, frio, inexorável. Em realidade, o turno de fala analisado, sobretudo entre as linhas 164-185, nos dá boas pistas de que, no universo das leis, há 
V. 9 (1) 170-189 jan-abr 2019

lugar tanto para argumentos de valor, no sentido de apreciação subjetiva, como discutido por Martineau (2010), quanto para argumentos técnicos, específicos do domínio jurídico. No excerto destacado, como mostramos, a experiência médica vivida por um dos magistrados em deliberação nos permite perceber que, em fim de contas, tal suscetibilidade diante do fato julgado atua também como um balizador para a definição de um dano moral. Desse modo, percebe-se ali uma matemática complexa mobilizada pelos magistrados, na qual se entrecruzam dois tipos de valores (valor afetivo + valor jurídico). Desvela-se ali, ainda, uma relação tópica do tipo "quanto mais distante de minha experiência, menor o meu envolvimento com o que se julga, ou o contrário, "quanto menor, maior".

Aliás, no excerto apresentado, vimos que a sensibilidade do magistrado o orientou na formação de seu entendimento. E isso apenas corrobora o fato de que, apesar de as regras no universo das leis serem rígidas (os códigos, as leis, a jurisprudência etc.), sabe-se que todo sistema jurídico assenta-se em um terreno movediço, repleto de elementos de incerteza. E tudo isso proporciona aos magistrados certa liberdade discricionária no momento de formarem sua convicção acerca dos julgados, no momento da qualificação de fatos. É, inclusive, possível que "a personalidade do magistrado exerça um papel, às vezes limitado, mas às vezes decisivo, no desenrolar de um processo" (PERELMAN, 1990, p. 590). Desse modo, a diversidade de parâmetros que intervêm em uma decisão, tais como os valores, experiência pessoal, normas e princípios jurídicos - e que os magistrados carregam consigo -, pode levar ao surgimento do conflito (estase) na mesa de deliberação, como acabamos de mostrar. E isso pode, inclusive, ser positivo, pois fará surgirem novas interpretações da lei, uma vez que, como nos alerta ainda Perelman (1999, p. 6) acerca do raciocínio jurídico:

[...] raras são as situações em que bons argumentos que defendem uma determinada interpretação não são contrabalançadas por outros argumentos bons ou ruins em favor de uma solução diferente para um mesmo caso.

Para concluir, precisamos dizer ainda que o território da lógica informal, na qual o raciocínio judiciário se encaixa, encarregase da descrição de raciocínios considerados como "menos ortodoxos", na medida em que as conclusões a que chegam são meramente verossimilhantes e raramente "corretas". Em resumo, e como já asseverava Toulmin (1993, p. 232), "a teoria do direito lida com 
enunciados jurídicos, deixando de lado um tratamento matemático de suas sentenças". Nos dados aqui analisados, pudemos perceber que, de fato, a passagem de uma regra abstrata para um caso concreto não é mero processo dedutivo; supõe, isto sim, adaptação constante das disposições legais a valores em conflito em controvérsias judiciárias. Ainda em acordo com Perelman (1990, p. 304), constatamos que:

[...] a ideia de que existem princípios de justiça análogos a princípios matemáticos e que, se corretamente aplicados trariam soluções justas, independentemente das circunstâncias, parece-nos absurdo.

Nesse sentido, por meio de estudos de caso como o que ora apresentamos, percebemos que, no domínio do dano moral, é muito difícil reduzir um raciocínio a um cálculo, a uma pesagem, a uma medida, na definição de um dano moral (REIS, 2010). No meio desse caminho haverá sempre uma "experiência vivida".

\section{Referências}

ALVA, C. et al. Interpretación jurídica. In: ALVAREZ, Q. F. La argumentation jurídica. Medellin: Editora Jurídica de Colombia, 2007.

ANGENOT, M. Dialogues de sourds - traité de rhétorique antilogique. Paris: Mille et une nuits, 2008.

ARNAUD, A. Du bon usage du discours juridique. Langages, n. 53, p. 117-124, 1979.

BERTEA, S. Legal argumentation theory and the concept of law. In: Proceedings of the Fifth Conference of the International Society for the Study of Argumentation, 2003. Amsterdam, p. 105-110.

BRETON, P.; GAUTHIER, G. Histoire des théories de l'argumentation. Paris: La découverte, 2000.

CANALE, C.; GIOVANNI, T. Inferring the ratio: commitments and constraints. In: FETERIS, E. et al., Argumentation and the application of Legal Rules. Amsterdam: Rozenberg Publishers, 2009.

COELHO, F. A. Reparação do dano moral: aspectos que devem ser considerados na fixação da forma ou do valor da reparação. São Paulo: Juarez Oliveira, 2009.

CORNU, G. Linguistique juridique. Paris: Éditions Montchrestien, 2005.

DAMASCENO-MORAIS, R. Le prix de la douleur: Gestion des désaccords entre magistrats, dans un tribunal brésilien de seconde instance. 2013. $491 \mathrm{f}$. Tese (Doutorado em Ciências da Linguagem) - Université Lumière, Lyon 2, França, 2013. 
v. 9 (1) 170-189 jan-abr 2019

DOURY, M. L'évaluation des arguments dans les discours ordinaires - le cas de l'accusation d'amalgame. Langage et société, Paris, p. 9-37, 2003.

DUPRET, B. Le jugement en action - ethnométhodologie du droit, de la morale et de la justice en Egypte. Paris: Droz, 2006.

GARAPON, A. et al., Les vertus du juge. Paris: Dalloz, 2008.

GOVIER, T. A practical study of argument. Wadsworth: Cengage Learning, 2010.

KOREN, R. Introduction. In: KOREN, R.; AMOSSY, R. Après Perelman quelles politiques pour les nouvelles rhétoriques? L'argumentation dans les sciences du langage. Paris: L'Harmattan, 2002.

LATOUR, B. La fabrique du droit: une ethnographie du Conseil d'État. Paris: La découverte, 2004.

LIVET, P. L'argumentation: droit, philosophie et sciences sociales. Canada: Les presses universitaires Laval, 2000.

MARTINEAU, F. Petit traité d'argumentation judiciaire. Paris: Praxis Dalloz, 2010.

MEYER, M. Histoire de la Rhétorique des Grecs à nos jours. Librairie Générale Française, 1999.

MORAES, M. C. B. Danos à pessoa humana: uma leitura civil-constitucional dos danos morais. Rio de Janeiro: Renovar, 2003.

PERELMAN, C. Rhetoriques. Bruxelles: Éditions de l'université de Bruxelles, 1989. Éthique et droit. Bruxelles: Éditions de l'Université de Bruxelles, 1990.

1999.

Logique juridique - Nouvelle rhétorique. Paris: Éditions Dalloz,

L'empire rhétorique - rhétorique et argumentation. Paris: Librairie philosophique J. Vrin, 2002.

PERELMAN, C. ; OLBRECHTS-TYTECA, L. Traité d'argumentation. Belgique: Éditions de l'Université de Bruxelles, 2008.

PLANTIN, C. Les bonnes raisons des émotions - principes et méthode pour l'étude du discours émotionné. Berne: Peter Lang, 2011.

Dictionnaire de l'argumentation - une introduction aux études d'argumentation. Lyon: ENS Éditions, 2016.

REIS, C. Dano moral. Rio de Janeiro: Editora Forense, 2010.

RICOEUR, P. Interpretación y argumentación. In: ÁLVAREZ, F. Q. La argumentation jurídica. Colombia: Editora Jurídica de Colombia, 2007. 
ROBRIEUX, J. La rhétorique et argumentation. Paris: Armand Colin, 2010.

STAMAKIS, C. Argumenter en droit - une théorie critique de l'argumentation juridique. Paris: Publisud, 1995.

TOULMiN, S. Les usages de l'argumentation. Traduction de Philippe de Brabanter. Paris: Presses Universitaires de France, 1993.

TRAVERS, M. Ethnomethodologie, analyse de conversation et droit. Droit et Société, n. 48, p. 349-369, 2001.

VANNIER, G. Argumentation et droit - introduction à la nouvelle rhétorique de Perelman. Paris: Presses Universitaires de France, 2001.

VIGNAUX, G. Argumentation et discours de la norme. Langages, n. 53, p. 6785, 1979.

WALTON, D. The place of emotion in argument. Pennsylvania: The Pennsylvania State University Press, 1992.

WOHLRAPP, H. Who is afraid of emotion in argument? In: Proceedings of the International Society for the Study of Argumentation, 2007. Amsterdam, p. 1509-1514. 